\title{
THE NATURAL HISTORY OF INSENSIBLE PERSPIRATION: A FORGOTTEN DOGTRINE OF HEALTH AND DISEASE
}

by

\author{
E. T. RENBOURN
}

\section{Insensible Perspiration. Early Times to Renaissance}

Mystical and religious beliefs have, from time immemorial, linked the life principle with air, breath and breathing; and in this may be the origin of the early conviction that not only the lungs but the whole body breathed in and out. The first clear declaration of such a dogma appears due to the Greek physician, Empedocles, who, from experiments with his clepsydra or water clock, concluded that as blood moved up and down the blood vessels, so were invisible airs and vapours squeezed out, or drawn into the body, through equally invisible pores of the skin and interior. This pulsatile ebb and flow through the pores was regarded by the Greek and later Latin writers, as a form of breathing -avarvon (anapnoe) or 'respiratio'. Hence the use of the related expressions

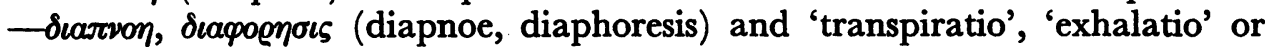
'perspiratio'-for this activity of the body. And, perhaps, to accentuate its

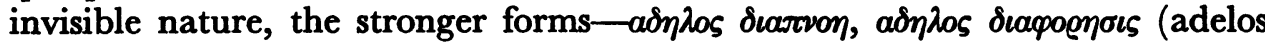
diapnoe, adelos diaphoresis) and insensibilis (occulta) transpiratio, exhalatio, perspiratio'-were sometimes used. Hippocrates referred to the matter on several occasions. 'Young children', said Theophrastus, 'are passionate and impetuous, and in general flighty, because the air, in large quantity, is excreted from their tiny bodies.'

Another dogma, certainly as old as Hippocrates, is that of condensation of water vapour, rising up from the hot body interior, or emerging from the warm skin, to form bile, urine, phlegm or sweat. Aristotle noted that the skin and flesh of animals was pervious to transpiration (diapnoe), a material which, said he, goes to form hair, scales and feathers. On the formation of phlegm in the cold brain, he pointed out that 'the process resembles, on a small scale, the one which produces rain showers'.

Galen rationalized these various ideas and built them into his complex system of physiology. The following are from various parts of his 'Works':

As the veins by mouths placed on the skin pass out whatever is redundant of vapours and smoke, so do they receive by the same mouths no small quantity of the surrounding air; and this is what Hippocrates means when he says the whole body breathes in and out.

And the other (excretion), which has no name because it is not commonly known, since it 


\section{E. T. Renbourn}

escapes observation on account of its tenuousness, is called insensible perspiration (adelos diapnoe) by those who consider it rationally.

Now, the amount of urine passed every day shows clearly that it is the whole of the fluid drunk which becomes urine, except for that which comes away with the dejections or passes off as sweat or as insensible perspiration.

Galen, elaborating on Empedocles, taught that air or pneuma ( $\pi v \varepsilon v \mu \alpha)$ was drawn from the lungs into the left ventricle, and through the skin pores into the whole body, by the simultaneous diastole of the heart and the skin blood vessels. The main functions of breathing were, he said, to cool the vital flame innate in the heart and to produce in the liver, left ventricle and the brain, the natural, vital and animal spirits necessary for growth, movement and feelings respectively. It was during the formation of the vital spirits that smoky or fuliginous vapours were produced; and it was throughout systole that the fuliginous and other excrementious vapours were expelled into the lungs and through the innumerable skin pores. According to Asclepiades and Galen, the aim of vigorous massage was to purge these pores and, thus, to cause the body to be 'well breathed through'. Galen also advised, for this purpose, the use of wine and anointing the skin with green aniseed oil.

Although the early physicians wrote a great deal on sweat-i $\delta \omega \omega s$ (hidros) or sudor-its relationship to insensible perspiration was, as might be expected, far from clear; and this relationship was to remain obscure to almost recent times. On occasion Galen took the common sense view that sweat simply came through the skin pores in the form of droplets. However, he sometimes accepted the old 'dew' theory and insisted that sweat arose from condensation of the insensible vapours by the action of a thickened skin or by an unwonted cold. This dual origin of sweat was to be argued over until the end of the nineteenth century. Galen believed that insensible perspiration was something innate, and, in health, was constantly liberated day and night. Liquid sweat was, on the other hand, a 'preternatural' discharge, a diagnostic sign of excess fluid in the whole body - as urine was of excess fluid in the blood vessels; and was produced only under conditions of great external heat, by the increased body heat of violent exertion or of fever, or arose from marked weakness in the expelling force.

A doctrine, long forgotten, but of considerable moment in the history of medicine, is that of suppressed or obstructed insensible perspiration. Many physicians of classical periods (Asclepiades, Themison, Soranus, etc.) accepted the so-called 'Methodist' theory of 'strictum et laxum' (tightening or loosening of atoms, corpuscles, pores or ducts); and there is frequent reference in the old literature to fevers and inflammations, and to disease in general, arising from the superficial or deep pores being too wide or narrow, asymmetric or kinked, clogged by the action of astringent drugs or cold air, and by excretions too profuse or too thick to pass out. Galen was, at times critical of 'Methodism', but he often accepted it; and in his book on 'Hygiene' he wrote a short chapter 'On the Causes and Treatment of Constriction of the Pores'. The following are from the 'Hygiene': 


\section{The Natural History of Insensible Perspiration}

In the insensible perspiration some of the denser excrement is eliminated, for this moreover there is need of more extreme producing heat and of more impelling force, or there is danger that it may be arrested at the skin before reaching its outlet.

And it is possible sometimes, also after bathing or sweating, or when the skin becomes otherwise relaxed from any other cause, for transpired air to produce some obstruction and thickening.

For such a disturbance of skin breathing, the Greek and Latin terms

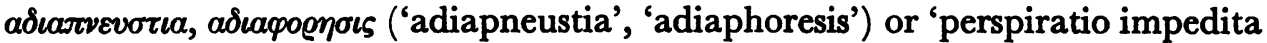
(suppressa, obstructa)' were commonly used. In order to release obstruction of the pores, Asclepiades and others sometimes prescribed-especially in the treatment of chronic disease-purging and vomiting and the 'hot regimen' of Petronas-heavy bedclothes, heated rooms, hot baths and drinks.

These various ancient ideas on skin function are given in some detail, for they were to recur, and sometimes as apparently new, during the following centuries. The Byzantine physicians of the first ten centuries A.D. often referred to disease arising from obstruction to the exit of vapours. Avicenna wrote thus on the 'bothor'-a skin disorder related to urticaria or, perhaps, to prickly heat:

It is due to obstructed transpiration from want of looseness of the skin increased by the condensing effect of the cool night air.

Two centuries later, John of Gaddesden, speaking of the Ephemera or One Day Fever, noted that:

The cause of it is in the grossness of the matter of the body or the blocking up of the pores from an external cause ... the heat of the sun or a fire, or from cold water; briefly anything that closes the pores and prevents the escape of vapours.

Lanfranc and de Mondeville wrote similarly.

During the Renaissance period, and later, the expressions sweat and insensible perspiration were sometimes confused, but, in general, used as they had been since classical times. Leonardi da Vinci noted that:

Air is generated in the heart, and this, as it becomes mingled with the warm thick atmosphere, evaporates through the extremities of the capillary veins at the surface of the skin in the form of perspiration.

Ambroise Paré (I554) thus copied Galen on the functions of the skin:

Lastly it is penetrated by many pores or breathing places, as we may see by the flowing out of sweat ... so the arteries, in the diastole, might draw in the encompassing air into the body for the tempering and nourishment of the fixed inbred heat, and in the systole expel the fuliginous excrements.

Perusal of the works of Fracastorius, Fernel, Ingrassia, Mercurialis and Foesius, shows that 'perspiratio impedita' and its consequences, were well known to writers of the sixteenth century.

For a better understanding of matters to be considered below, some reference 


\section{E. T. Renbourn}

must here be made to the doctrine of 'consent' or 'sympathy' (later to be called 'vicarious' action), a physiological doctrine which may be regarded as a logical outgrowth of both sympathetic magic and the humoral theory. The concept of 'sympathy' was based on age-old clinical observation, and stressed the relationship, thought to exist, between the organs, or their secretions, in health and disease. Plato believed in a 'sympathy' between the body and soul. Over the centuries the idea evolved that 'consent' existed between the skin (sweat, transpiration), kidney (urine), stomach (appetite, vomiting), the bowels (diarrhoea, constipation) and other organs. Galen believed that 'consent' was brought about by the passage of animal spirits through the hollow nerves to the structures involved. Various forms of 'sympathy' were accepted-'remote sympathy', between widely separated structures-as in the example of womb and breast given by Hippocrates; 'continuous sympathy', where the lining of one structure passed into that of another-the skin and alimentary canal-as inferred by Hippocrates and Galen; and 'contiguous sympathy'-between organs in close proximity-as, for example, the skin and underlying lungs, kidney, stomach or bowel. Excitation of the 'contiguous sympathy' was sometimes put forward as an explanation of the empirical value of blistering agents, of cupping and of leeches (counter-irritants, antiphlogistics or discutients).

It was, perhaps, the doctrine of 'sympathy' which excited the ever present fear of the 'rash struck in' or of obstruction to secretions, excretions, blood and other discharges, from the nose, mouth, lungs or bowel; from the womb or breast; from a tumour or ulcer; or from the great 'common emunctories' (excretory channels), the kidneys and the skin. For, it was said, such obstruction must lead to a plethora of vapours and humours and, by increased motion or friction of the particles, or by the action of absorbed miasms or retained morbid putrescent matters, produce fevers and inflammations. The obstructed substances might be directed by 'metastasis' to the nose with a catarrh or nose bleed; to the lungs with cough and inflammation; to the brain with headache, melancholia or phrenitis; to the stomach with deranged appetite or vomiting; to the kidney with profuse pale urine; to the subcutaneous tissues with rheumatism, gout or dropsy; and to the bowel with diarrhoea, dysentery or even cholera. These various ideas can be traced to Galen or earlier.

\section{Sanctorius and the Nerw Methodism}

It is generally believed that the concept of insensible perspiration, of the lungs and skin, arose with Sanctorius; but, in 1614 $_{1}$, when his Ars de Statica Medicina was published, this concept was already some twenty centuries old. As pupil and friend of Galileo he became greatly drawn towards the quantitative approach to science; and it is in the quantitative that lies his permanent contribution to medicine.

It is a new and unheard of thing in Medicine [wrote the immodest Sanctorius] that anyone should be able to arrive at an exact measurement of Insensible Perspiration. Nor has anyone, either Philosopher or Physician, dared to attack this part of Medical Inquiry. Indeed, I am 


\section{The Natural History of Insensible Perspiration}

first to make the Trial, and, unless I am mistaken, I have by Reasoning, and the Experience of thirty Years, brought this Branch of Science to perfection.

This experience he gained by weighing himself, his food and his various excretions, on a steel-yard balance on which, it is understood, he remained during the day and slept at night except during his frequent travels in Italy and to Poland.

Although Sanctorius made no reference to his predecessors (not an uncommon practice in his time and later), the substance of many of his Aphorisms can be traced to Galen-whose 'dew' theory of sweat formation he also re-established. It would appear that Sanctorius was unaware that, in 1450, Cardinal Cusanus or Nicholas Krebs, also a graduate of Padua, had suggested the value of static (weighing) experiments in the study of blood and urine. Furthermore, in the third century B.c., Erasistratus 'had already dared to attack this part of Medical Inquiry' by weighing fowls and their food and excreta. From the results of his static experiments (of which no details are given) Sanctorius concluded that the insensible excretion, from skin and lungs, was by far the most important of all the 'servile evacuations', and upon its uninterrupted free passage through the pores depended health and contentment. When, from any cause, the sensible excretions were increased, the flow of insensible excretions were simultaneously hindered or suppressed. To the insensible excretion he gave the synonymous expressions - 'matter of perspiration', 'insensible perspiration' or, quite plainly, 'perspiration'. From this time onwards, and until almost the end of the nineteenth century, the word 'perspiration' was to mean, in general, not visible droplets of sweat but only the invisible vapours of the body. Drugs encouraging 'perspiration' were sometimes known as diaphoretics; those promoting sweat being the sudorifics. There were, by modern standards, innumerable inherent errors in the static experiments, and it is pretty clear that neither Sanctorius nor his followers attempted to separate, quantitatively, sweat from 'perspiration'.

Perusal of the 'Ars Statica' shows that Sanctorius was concerned more with the Galenic six 'non-naturals' (air, food and drink, sleep and watching, rest and exercise, excretions, mental activity) than with diseases or 'contra-naturals'. Nevertheless, he indicated that obstruction to the 'matter of perspiration' by cold or damp ('Of Air and Water'), or by depressive and violent passions ('Of Affections of the Mind') could, particularly in the summer time, lead to fevers, inflammations and disease of the organs.

The resuscitated Methodic doctrine slowly spread over Europe, and everywhere was hailed as a new landmark in medicine. A reference to Aristotle's remark on the origin (from transpiration) of hair and scales, suggests that Francis Bacon (1627) was as familiar with the 'diapnoe' of the Greeks as with the 'perspirable matter' of Sanctorius. It is said that Charles II encouraged static experiments, some reference to which is given in Pepys' Diary (1662). Henry Power (1664) was well conversant with the 'Ars Statica' and wrote on the 'perspiration' of plants. Thus said Thomas Trapham (1679), son of Gromwell's Surgeon-General: 


\section{E. T. Renbourn}

Hence what's usually carried off by sweating and a more silent daily breathing through the whole skin rebounds inwards and condenses to an ichorous water. ... Transpiration according to the Statica Medicina is very considerable.

Louis Cusac, in 1682, advised 'esprit de vin' in hot water for keeping the pores open, but even this had been advised by Galen. Perusal of the works of Sydenham shows no mention of Sanctorius, but as Sydenham was oblivious of most of his predecessors, this is, perhaps, not unexpected.

Sanctorius noted that retained 'perspirable matter' could produce not only miasms but 'ticks, lice and the like', an idea perfectly acceptable at the time. John Mitchell ( I 744) noted:

The perspirable matter of black or tawny people is more subtil and volatile in nature, more acrid and penetrating ... and more apt to degenerate to a contagious miasm than the mild effluvia of whites.

In his treatise on 'Cleanliness', Johann Platner ( 1752 ) insisted that, for the free passage of the 'insensibilis transpiratio', the air spaces in clothing had to be free of dirt; and, since retained secretions could putrefy and be reabsorbed, advised daily washing of the body and underclothes-a state of personal hygiene rarely met with in his day.

During the seventeenth century, and later, there was great controversy as to how the insensible perspiration passed out of the skin. Skin glands had been noted in 1664 by Steno; Malphigi, two years later, assumed that they had a special duct (as in the case of the salivary glands) through which the sweat passed out; and Robert Boyle, in I685, spoke of the 'miliary glandules' of the skin. One might, therefore, conclude that the origin of sweat was well understood at this time. In point of fact, however, up to the nineteenth century little or nothing was known of the real nature of cutaneous glands, and 'miliary glandules' were regarded-as they were first by Ruysch-simply as the termination of the 'perspiratory' vessels or 'exhaling' arteries of the skin, through the pores of which the insensible perspiration (or the sweat) flowed out. Although pores of the skin had been known from Empedocles onwards, nobody had ever proved their presence, and many believed they did not exist. Leeuwenhoeck stated that the 'perspirable matter' found its way between the scales of the epidermis, and later Albinus and others likened its passage through the skin to 'streams of warm water passing through dried leather'. Some even described valves, on the ducts or pores, capable of obstructing the passage of the transpiration. Liquids, air or miasms were believed taken into the skin through special 'absorbents' (opening below the skin surface), identified, by many, with the lymphatic vessels.

\section{Chills and Obstructed Perspiration to the Seventeenth Century}

Throughout history man has been dogged by fear of the dire consequence of a chill or 'catching cold', vague terms used to signify not only any sudden cooling of the body and what is known as coryza or the common cold, but also 


\section{The Natural History of Insensible Perspiration}

the rigor, or sensation of chilling, occurring at the onset of certain fevers. As will be noted further, the terms chill, 'catching cold' and obstructed transpiration were often used as meaning the same. Over the centuries there was apprehension of chills said to arise from a cold wind, damp night air or early morning dews; from soaked clothing, wet feet, damp houses or beds not aired.

Hippocrates said:

wherefore one should attend to this; that when the feet are cold the bowels are filled with nauseous matters

an early reference to the 'sympathy' of the skin and alimentary canal. Asclepiades noted that, in winter, cold air enters the pores and chills the body. Thus said Galen:

What is there to wonder at, then, if something should be transferred from the extreme skin surface and so reach the intestines and stomach? ... And this is therefore neither unlikely nor impossible ... when the part adjoining the skin becomes suddenly contracted by unwanted cold.

In $155^{2}$ John Caius mused:

On this wise be advised how to order yourselves ... for fear of unwont ayer, or forcying nature by soubdaine sticking in of the same aier, cold or evil into the open body. For nature so forced maketh often tymes a sore and soubdaine fluxe, as wel as avoidance of these humours by sweate as of others by purgation.

Sanctorius had a reasonable attitude to the effect of cold on the body; for, said he:

being exposed to a cold Air, after Heat, by leaving off Garments, a Body may perspire thereby in the space of a whole Day about two Pounds the less and perceive no harm thereby. . . . External Cold hinders Perspiration in weak People . . . but in the robust it increases it.

Cold naturally stops the pores, [said Nicholas Culpeper] congeals the humours, stops sweate, staies motion, and by this it so stops the power of the spirits that it consumes the strength of heart and bowel ... . for cold bindeth and keepeth vapours within the skin.

Robert Boyle reflected on cold in a way reminiscent of Asclepiades.

Wind by its motion, [said he] is able not only to drive away the air contiguous to the hands and face and the warm steams of the body which tempered its coldness, but to pierce deeper than the calm air is wont into the Pores of the body.

At the end of the seventeenth century John Floyer ( 1697 ) made a strong case for cold baths as a means of maintaining health; for, said he:

... by the experiments mentioned, 'tis evident that Cold Baths heat the body by stopping the Pores and keeping in the hot effluvium or aerial Spirits.

The part played by flannel clothing in combating chills and obstructed 'perspiration' has been dealt with elsewhere in these pages (Renbourn, 1957). 


\section{E. T. Renbourn}

\section{Obstructed Perspiration and Disease: First Half of the Eighteenth Century}

The eighteenth century was, par excellence, the period during which the ideas of Sanctorius became fully elaborated into the new Methodism. The classical expressions 'diapnoe', 'adiapneustia' and 'perspiratio impedita' were now to be found in the medical dictionaries of Castelli, Blancard and Quincy, etc. Throughout Europe it became fashionable to write dissertations on suppressed 'perspiration' ('transpiration arretée': 'verhinderte Ausdünstung') and the part it played in various diseases. Some even explained the ancient belief in the rejuvenation of dotards, by consort with young girls, on the sympathetic infusion through the old skin of the vigorous and youthful insensible vapours.

William Cockburn ( 1 70I) firmly stressed that cold or damp was an important cause of abdominal flux.

Now, [he argued] the Quantity of Perspiration being less, because of the Blood's thickness, the transpirable Matter will be separated at the Parts where the Blood is most fluid and where the watry Parts are commonly secreted. But these parts are nearest the ... Heart, and the Guts being in this Vicinity, the difference of transpirable Matter, unsecreted in the Glands of the Skin, will be secreted at the Glands of the Guts.

These ideas may not be clear to the modern reader, but a so-called logical argument, rather than the objective experiment, was the way to convince the majority of Cockburn's readers.

Jeremiah Wainewright ( 1 707) wrote thus:

Besides, the Cold, closing the Pores of the Skin, will hinder Perspiration, and thereby increase the Quantity of Blood which will pass through the lungs yet more difficultly. And it is on this Account also that the Patient falls into a Diarrhoea; the Passage of the Serum through the cutaneous Glands being stopp'd, it solicits those of the Intestines. But if an entrance is refus'd here, the legs swell, and asthmatic symptoms increase.

In I7 I4 Daniel Turner, with the aid of his 'indifferent glass', undoubtedly saw the pores of the skin. On the 'Twofold Perspiration' of the skin he wrote:

That it is everywhere perspirable is as clear from the Steams and Vapours in all parts of it exhaling, and often appearing in the form of dew upon the surface of the same. Pores ... are to ventilate the circulating Blood and to discharge the fuliginous Excrements with the Steams arising from the adjacent parts. Further, from the constriction or constipation of the cutaneous Pores by the ambient Air, especially when the Body, before hand put into a Heat, is suddenly exposed thereunto, the serous Particles which used to fly off continually in Vapour, being now past in, excite the Intestine to feverish excitement. . . . Diseases infecting Mankind, according to the Computation of the judicious Sydenham, are two-thirds Fevers, and very probably take their rise from Perspiration hindered.

John Keill ( 17 I8) was one of the earliest critics of Sanctorius. For a whole year he kept 'Journals of Perspiration' in which he tabled, day by day, the weights of his food, 'perspiration', stool, urine and condition of the atmosphere. $\mathrm{He}$ found the insensible perspiration to be often less than the sensible secretions. Sanctorius, he said, was in error because, in the static experiments, absorbed air 


\section{The Natural History of Insensible Perspiration}

had not been taken into account; furthermore, in the hot climate of Padua, one would naturally expect both sensible and insensible perspiration to be greater. Keill would not accept the idea that obstruction of the insensible secretion was a cause of disease. The effect of damp or cold was, in his opinion, not due to a block of what came out of the skin pores, but, rather, to an ingress of 'frigorick' particles,

of a nitrous kind, capable of chilling, condensing and thickening the animal fluids.

Bryan Robertson found fault with the critic, saying that Keill:

often drank Punch and was much on horseback, both of which provide Urine much more than they do Perspiration.

In his Commentaries on the 'Ars Statica', John Quincy ( 1720 ) wrote:

When the coldness of the external Air lessens the Insensible Perspiration that way, either the sensible Evacuations are increased or greater Quantities are carried off by Respiration by the lungs ... or perspired into the cavities of the Guts with griping and great uneasiness.

The assumption of a sympathy between the two insensible channels is of interest, and is periodically met with in the literature. (Wainewright 1707 , Cruikshank I 785, Bichat I 802).

The work of Richard Towne (I 726) can be regarded as one of the earliest English texts on tropical medicine. In this he wrote:

A diminished Perspiration will likewise contribute towards enlarging the Orifice of the hepatic and pancreatic Ducts, and on this account the Secretion of the respective Juices will be more plentifully made into the Intestine, and hence be an additional source of looseness.

Jacques Winslow (1732) satisfied himself of the existence of insensible perspiration by opposing his naked head to a white wall on a fine summer's day; the vapour magnified by the sun's rays, was seen ascending like smoke from his head. Boerhaave, earlier, had done the same by placing his warm hand in an ice box, when a smoke was seen to arise like breath on a winter's day. Stephen Hales ( I 733) appears to have been the first to weigh separately the insensible perspiration of lungs and skin. He found 'perspiration' of plants to be, weight for weight, much greater than that of man.

In the same year John Arbuthnot wrote lengthily on the functions of the skin.

For, it is plain [he said] that since the outward Air enters the Pores of the Body, and is sometimes imbib'd and absorbed by the Animal, the Quantity of perspirable Matter is the difference of the Excess of that beyond the Quantity of Air that is imbib'd. Moisture helps Air to insinuate itself into the Pores of Bodies ... as fixt and dry alkaline Salts do. . . . The Symptoms which one feels in extremely hot Weather . . . Rheumatism, Gouts and Diarrhoea are both by suppression of the Perspiration and by a sudden admission of all this Serosity through the Pores of the Skin.

Arbuthnot's idea on the quantity of 'perspirable Matter' was based on the work 143 


\section{E. T. Renbourn}

of Keill. In 1734 George Rye published results of statical experiments carried out in South Ireland. He also criticised Keill, noting that, as the latter went to bed very late and made experiments very irregularly, the experiments could hardly be very reliable. Two years later, Jean de Gorter recorded an increase in his weight after sleeping all night under heavy bedclothes. This was the sort of proof put forward for the absorptive function of the skin. John Lining ( 1744 ) of South Carolina repeated the work of Sanctorius

with the weight of the cloaths taken care of

-a matter not considered before-and, as might be expected, differed from the master in a number of important respects. As an afterthought he added:

likewise I would have added an Analysis of a little of my Blood and Urine in every Month, with the Blood's Cohesion, could I have got the Instruments.

Army Surgeon De Meyserey ( 1744$)$ noted that:

The soldier has most to fear from arrested transpiration and this will arise from the least impediment to abundant sweats.

Pinard, another Frenchman, in his dissertation on Miliary Fever (1 747), put forward the view (quite widely accepted) that this disease also arose from obstructed transpiration. John Wesley, the Cleric, was a follower of Floyer.

Cold bathing [said he] is of great advantage to Health. It promotes Perspiration, helps the Circulation of the Blood, and prevents Danger of catching Cold.

Nevertheless, he added:

Obstructed Perspiration (commonly called catching Cold) is one great source of Disease. Whenever there appears the least Sign of this, let it be removed by a gentle Sweat.

Bryan Robertson (1748), reasoning from his own static experiments, commented that:

A firm belief in the Doctrine of Sanctorius has hurt many. For it is natural for Persons thus persuaded, if they awake in the Morning and finding Moisture on the Skin, to be afraid lest they check Perspiration, and to continue in bed until the Moisture goes off by itself; by which erroneous Conduct they relax and weaken the Constitution and frequently become Valetudinarians.

At the time many believed that cold produced its effect, not by suppression of insensible perspiration, but, by contracting the superficial blood vessels and forcing blood into the internal organs. This idea, however, is certainly as old as Galen. 


\section{The Natural History of Insensible Perspiration}

\section{Insensible Perspiration, Damp Air, Evaporative Cooling: Second Half of the Eighteenth Century}

In spite of the critics, Sanctorian Methodism continued unabated. John Pringle (1752) wrote on bowel disease in the British Army:

A sudden stoppage of Perspiration [he said] coming upon a relaxed Fibre and putrescent state of the Blood, if not remedied, will generally occasion a Vomiting, Intermittent Fever, Flux or Cholera. ... .

William Hillary ( 1759 ) practitioner of the West Indies, questioned:

Was not the Dysentery and the Aphthous Fever caused by the falling of so much Rain rendering the Air cooler, by which the great Perspiration and the Sweating, caused by long continued Dryness and heat before, being suddenly abated and stopped; and were they not turned into the Bowels and the Humours being rendered acrid by that Heat so produced the Disease?

In the same year Francis Home, of Edinburgh, repeated some of the experiments of Sanctorius, but could draw no valid conclusions.

There is no Discovery, [he concluded] next to that of the Circulation of the Blood, that has so much affected our Reasoning in Medicine as that of insensible Perspiration. The origin of most Diseases and the operation of most Medicines are accounted for from it. Sanctorius . . . his particular conclusions meet with less credit especially when we discover his reason is often trifling and erroneous.

The text-book of Albrecht von Haller was the standard teaching during the second half of the eighteenth century. He suspected that sweat came from the glands of the skin. As for insensible perspiration, this was the

redundant water of the blood and its alkaline impurities rendered more acrid by repeated circulations, together with an extremely volatile oil.

On the basis of the work of Stephen Hales on pulmonary 'perspiration', Haller taught that cutaneous transpiration was less than half of that claimed by Sanctorius.

The exhalation is easily demonstrated in many ways [he said]. A light mirror when held near the warm and naked skin is quickly obscured by a moist vapour.

Haller also taught that the 'exhaling' (or 'inhaling') vessels of the skin could, in some way, be relaxed or contracted by the nervous power, thus giving basis for the Sanctorian (or earlier) doctrine that a cheerful disposition encouraged, and a melancholic state hindered, the exit of 'perspirable matter'. This may, perhaps, be related to the eighteenth-century expression - 'to have the vapours' ('hypochondria', 'spleen', hysteria, etc.).

John Chandler (176r) stressed that insensible perspiration passed not only through the skin but into all the internal Surfaces keeping them moist and preventing adhesions and added: 


\section{E. T. Renbourn}

it is the perspirable Matter, preternaturally inspissated, which forms the tenaceous Substance called Size that appears on the upper surface of Blood drawn upon opening a Vein.

In 1772 Jean Colombier, Inspector-General of French Military Hospitals, noted:

The humidity of the air is one of the most frequent causes of disease in our soldiers. . . . The vapours of the air are retained in the skin and oppose those which pass out. Transpiration is thus markedly affected and may be totally intercepted.

William Cruikshank believed that the skin absorbed water and liberated something which turned lime water turbid. In 1778 he weighed condensed insensible perspiration given off by a hand sealed in a glass bottle and covered by a chamois leather glove. Cruikshank could not reconcile himself to the 'dew' theory of sweat:

for the sweat is most copious when there is least time allowed for condensation of the insensible perspiration; nor has it been proved that the surface of the body is thus colder or more capable of condensing this vapour than at any other time.

On skin pores he added:

I own that after some pains, and assisted with a pretty good microscope, I have not been able to discover perforations in the cuticle or rete mucosum. . . . I believe, nevertheless, that they certainly exist.

Cruikshank ascribes the difficulty in finding the pores to the elasticity of the skin which kept them closed except during the passage of the 'perspirable matter'. He believed that in both health and disease, pulmonary 'perspiration' was at least as important as that of the skin. Abernethy ( 1 793) showed that not only did the skin transpire, but it truly breathed ('aërial perspiration')absorbed oxygen and liberated carbonic acid.

From earliest times it was held that, since air and its contents passed freely into the skin, a man was affected by the air he lived in. Furthermore, a damp air, by stimulating the 'absorbent vessels' of the skin, entered more easily than a dry one. Not only did a damp or foggy atmosphere chill the body but it could also produce fevers and pestilences. Such an air was said, by some, to 'debilitate' the cutaneous blood vessels and hence impair the natural force expelling the insensible perspiration through their walls. Others-Arbuthnot, Colombierbelieved that damp air (or, perhaps, its contained miasms) simply produced a mechanical block to the exit of the humid insensible excretions. Edward Rigby ( 1785 ) offered a somewhat more objective interpretation-based, it may be, on the work of Rumford-for, said he,

a moist air is a better conductor of heat than when dry. [Rigby continued] I have no doubt but that some moisture does escape insensibly from the skin, but I am persuaded it is much less than commonly supposed ... and ... I cannot help conjecturing that what has usually been termed by medical writers insensible perspiration is, in some degree, the mere escape of the matter of heat. 


\section{The Natural History of Insensible Perspiration}

It had always been common knowledge that as the weather became hotter so the amount of sweat increased, and Sanctorius had first demonstrated (but, to his own satisfaction) that the 'matter of perspiration' was also greater. The value of evaporating water as a cooling agent was known for centuries in the East, but the real causal relationship between evaporation and cooling had never been seriously suspected in Europe. In 1755 William Cullen of Glasgow, demonstrated the truth of the matter, but it was left to Benjamin Franklin, a few years later, to apply the concept to the human body. Although, by 1764 , Black had determined the latent heat of evaporation of water, and Blagden, some ten years later, demonstrated the cooling effect of sweat, Rigby, as noted above, had but an inkling of the real function of insensible perspiration. James Currie (1797), however, made the matter clear:

In discussing the subject with my late ingenious friend, Dr. Bell, [said he] it suggested itself to me that the principle office of the insensible perspiration might be to regulate the animal heat. . . . Under this point of view, which has been hitherto almost wholly overlooked by physiologists, perspiration assumes its true character and becomes an object of the first importance in health and disease.

Unbeknown to him, seven years previously, Lavoisier and Seguin had read a paper on 'Transpiration in Animals' in which they showed that the essential function of insensible perspiration was the control of animal heat produced within the lungs. By completely enclosing himself in a gummed silk bag, and collecting expired air through a copper mouthpiece, Seguin, for the first time after Hales, weighed separately the two varieties of insensible excretion. It was also shown, pretty conclusively, that the skin absorbed neither water nor gases.

Treatises on medicine continued to encourage preoccupation with the intangible insensible perspiration, but had at no time given advice on how to diagnose its obstruction - even with the aid of a balance. If the heroic doses of 'stimulants' (opium, brandy) demanded by the Brounonian doctrine of 'strictum et laxum' sent patients to an early grave, the widespread uncritical attitude to the Methodism of Sanctorius must have produced ill health in far greater numbers. Because most febrile diseases were believed to arise from obstructed transpiration, there was, throughout Europe, general application, by physician and quack, of the age-old 'hot' (or 'Netherland') regimen' - the use of all internal and external means of producing prolonged and drenching sweats-in order to open, at all costs, the supposedly closed pores of the skin. It is very possible that, as a consequence, the sweat ducts did, in fact, become blocked, with a resulting sudaminal rash. This may have been an important cause of Miliary Fever or 'Miliaria Clinica' so common during the seventeenth and eighteenth centuries.

\section{Obstructed Insensible Perspiration: Nineteenth Century}

The controversy on 'aërial perspiration' which had raged at the end of the previous century was admirably reviewed, in 1807 , by Daniel Ellis. At this period Buchan's 'Domestic Medicine', and other standard texts, still listed the 


\section{E. T. Renbourn}

following among diseases arising from obstructed insensible perspiration; most febrile disorders, gout and rheumatism; inflammation of the lung, kidney, bowel and brain; scurvy, asthma, epilepsy and hypochondria. James Johnson (1813), grand old man of Indian tropical medicine, made a strong case for 'sympathy' between the skin and internal organs, particularly the bowel and liver, but appeared unaware that the idea was anything but new. Diarrhoea and dysentery were, he said, due to 'perspiration thrown into the bowels', but were not associated with increased bile secretion as claimed by earlier authors. When, in 1824, William Edwards demonstrated that, in man and animals, the amount of insensible perspiration appeared to be much greater in a dry than a moist atmosphere, he seemed to have confirmed the old idea that a damp air obstructed the 'exhalent' vessels. He argued, however, that, although cold moist air was a better conductor of heat, it chilled the body no more than did a dry air at the same temperature, because of the simultaneous decrease in insensible perspiration. Furthermore, he said, since the latter was derived from a general transudation of water through the skin (a 'vital' action), it could, clearly, be neither suppressed nor obstructed during life. This early serious criticism of the Sanctorian Methodism, nevertheless, went by unheeded. John Bostock (1826), chemical collaborator of Richard Bright, pointed out that the carbonic acid emitted (and oxygen absorbed) by the lungs and skin should be taken into account when considering the amount of insensible perspiration. In the following year Walter Dendy introduced another chemical observation, albeit obscure.

The sweat [said he] appears to rise from the perspirable matter of Sanctorius being too much increased in quantity, and from its hydrogen combining with the oxygen of the atmosphere and assuming a liquid form.

Andrew Combe (1834) wrote lengthily on the functions of the skin, and stressed the danger of retained 'perspiration'. Although believing in the physiological 'sympathy' of skin and bowel, he added:

I do not mean to affirm that an effect is produced by a physical transference of suppressed perspiration ... but the waste matters will be thrown to one or other of the excretory organs:

In his book on 'Dropsical Diseases', Jonathan Osborne (1837) put forward the view (almost as old as Hippocrates) that such disorders arose from cold and damp and the consequent suppression of 'perspiration' - which he believed to be the cause of both the dry skin and diarrhoea.

In 1844 Fourcault published the results of experiments in which he painted the skin of animals with impermeable varnish. He found a 'vicarious' or 'sympathetic' congestion of mucous membranes, enlargement of the liver and inflammation of the bowels; and concluded that suppression of insensible perspiration, arising from cold and damp and insufficient exercise, was a potent cause of chronic disease in man, especially of diarrhoea, scrofula and even pulmonary consumption. 


\section{The Natural History of Insensible Perspiration}

Confusion between the two varieties of perspiration continued (Renbourn 1958). Strangely enough Breschet (1835) revived the old Greek expression 'diapnoe' to describe the newly discovered sweat gland apparatus-'l'appareil diapnogène'. It was now realized that the 'perspiratory' vessels or 'exhaling' arteries of earlier authors were nothing but the recently described sweat ducts. Krause (1844), whilst accepting the glands as the main source of sweat ('Drusensschweiss'), nevertheless believed that, under many common circumstances, it could arise from condensation of insensible perspiration ('Dunstschweiss'). Arguments were long to persist as to whether insensible perspiration itself arose from the sweat glands or, as suggested by Edwards, a general transudation through the skin. Coulier, in $185^{8}$, demonstrated that dry flannel clothing prevented the chill of damp air by the liberation of latent heat (arising from condensation within the wool fibres of 'l'eau hygroscopique') derived from both insensible perspiration of the skin and the water vapour of the atmosphere. In 1867 Erasmus Wilson wrote:

The function of the skin as regulator of the body temperature and a purifier of blood is affected by means of a peculiar secretion, the perspiration. When condensed or poured out in a fluid state, it is termed sensible perspiration.

Similar statements appeared later in the standard medical dictionaries (Littré and Robin, 1874, Thompson 1882 and Franck 1884).

After the second half of the century less attention was given to insensible perspiration, and the terms suppressed or obstructed 'perspiration' began to disappear slowly from the literature. The development of experimental physiology and biochemistry gradually threw light on organ function; and it began to emerge that the main excretory organ of the body was the kidney and not the skin. When the theory of spontaneous generation was discarded by Pasteur, it became clear that the development of miasms or insects in putrefying 'perspiration' was but a myth. At this stage Pettenkofer (1862) introduced the 'anthropotoxin', a supposedly noxious chemical excreted in the transpiration of skin and lungs and capable of reabsorption. This revival of an old Greek doctrine was not dispatched until the end of the century, by which time it was fully realized that skin absorption of either air, water or water vapour was but of little consequence. The following appeared in Quain's revised Dictionary of Medicine (1894) - a work written for the expert:

Vicarious diarrhoea. Embarrassment or suppression of the functions of the skin, kidneys or lungs ... may lead to the bowels performing additional excretory work. . . . Diarrhoea from chills (suppressed perspiration) is a common instance.

Schäfer's massive text book of physiology, published two years before the new century, reviewed existing knowledge of animal heat, sweat, water absorption and respiration of the skin; but insensible perspiration appears to be nowhere mentioned. 


\section{E. T. Renbourn}

\section{Epilogue}

By the beginning of the twentieth century the 'dew' theory of sweat had quickly withered by disuse atrophy, and the words sweat and perspiration had, after many centuries, become synonymous. Abundant proof existed that the skin could no longer be regarded as an organ of excretion. Knowledge of reflex action and the new science of endocrinology had thrust 'sympathy' and 'vicarious' action into the limbo of teleology. Physiologists now taught that osmosis and evaporation were the main factors in the control of insensible perspiration (Whitehouse et al., 1932); the sweat glands were, apparently, not concerned. There was now no purpose in declaiming, as Edwards had a century before, that insensible perspiration could be neither suppressed nor obstructed; for the Methodism of Sanctorius was already buried and well forgotten.

Modern text books of physiology give but scant attention to the subject of insensible perspiration; but the last word on the matter has, perhaps, not yet been said. There is still lingering doubt as to its origin; and recent work suggests that some of the old Greek ideas may, nevertheless, be true-that both water and its vapour can, under certain circumstances, be absorbed into the skin (Buettner 1953).

No longer are the doctrines of Sanctorius a matter of controversy, but the static experiments have been resuscitated by the use of the 'matter of perspiration' for calculating basal and total metabolism (Benedict and Root, 1926; Jores, 1930; Newburgh et al., 1931).

\section{REFERENCES}

Abernethy, J. (1793-7), Surgical and Physiological Essays.

Arbuthnot, J. (1733), An Essay concerning the Effect of Air on Human Bodies.

Aristotle (1955), Parts of Animals. Trans. Peck, A. L.

A vicenna (1555), Liber Canonis de Medicinis Cordialibus. Venice.

BACON, F. (1627), Sylva Sylvarum or a Natural History in Ten Centuries.

Brnedict, F. A., and Root, H. F. (1926), 'Insensible Perspiration; its relation to human physiology and pathology,' Arch. Int. Med., xxxvm, 1.

Bichat, M. F. X. (1802), Anatomie Générale appliquée da la Physiologie et d la Médicine. Paris.

Bostock, J. (1826), An Elementary System of Physiology.

BOyLe, R. (1665), New Experiments touching Cold, etc.

BOYLE, R. (1685), An Experimental Discourse on the Insalubrity . . . of the Air.

Breschet, M. G., and Roussel de VAuzìme, M. (1835), Nouvelles Recherches sur la Structure de la Peau. Paris.

Buchan, W. (1807), Buchan's Domestic Medicine Modernized, etc.

BuettNer, K. (1953), 'Diffusion of Water and Water Vapour through Human Skin', 7. appl. Physiol., vi, 229.

Carus, J. (1552), A Boke or Counseill against ... the Sweatying Sicknesse.

Ghander , J. (1761), A Treatise on the Disease called a Cold. 2nd ed.

CockBURn, W. (1701), Nature and Cure of Fluxes.

Colombier, J. G. (1772), Code de Médicine Militaire pour le Service de Terre. Paris.

Cомв e, A. (1834), The Principle of Physiology applied to the Preservation of Health. Edinburgh.

Coulier, Prop. (1858), 'Experiences sur les Etoffes', F. Physiol. (Paris), i, 122.

Cruikshank, W. C. (1 785), Experiments on the Insensible Perspiration of Human Bodies, etc.

Gulpe Per, N. (1655), Culpeper's Last Legacy, etc. 


\section{The Natural History of Insensible Perspiration}

GURRIe, J. (1797), Medical Reports on the Effeot of Water... in Fever and other Diseases.

Cusac, L. (1682), Traite de la Transpiration des Humeurs, etc. Paris.

Cusanus, N. (1922), 'Opuscula Varia'. Cited by Viets, H. R. Ann. Med. Hist., iv, 127.

Dendy, W. (1827), A Treatise on the Cutaneous Diseases incident to Childhood.

EdW Ards, W. F. (1824), Sur l'Influence des Agens Physiques sur la Vie. Paris.

ElL1s, D. (1807), An Inquiry into the changes induced in the Atmospheric air . . . by the Respiration of Animals, etc.

Erasistratus (1949), Cited by Farrington, B. Greek Science, vol. 2.

Floyer, J. (1697), An Inquiry into the right use ... of Baths in England.

Fourcault, A. (1844), Hygiène des Personnes Predisposées aux Maladies Chroniques. Paris.

Gaddesden, J. (1929), Rosa Anglica. Joannis Anglici. Ed. Wulffe, W.

GaLEN (1833), Opera quae extant. Ed. Kühn, C. G. I, 82 I. Leipzig.

Galen (1928), On the Natural Foculties. Trans. Brock, A. J. Cambridge, Mass.

Gale N (195I), De Sanitate Tuenda. Galen's Hygiene. Trans. Green, R. M. Springfield.

Gor te R, J. DE (1736), De Perspirations Insensible Sanctoriana, etc. 2nd ed. Leyden.

HALES, S. (1 733), Statical Essays.

Haller, A. von (1757-66), Elementa Physiologiae. Trans. 3rd Latin ed. Edinburgh.

Hillary, W. (1 759), Observations on the Changes of the Air and concomitant Epidemical Diseases on the Island of Barbadoes.

Hip pocrates (1849), The Genuine Works of Hippocrates. Trans. Adams, F.

Hip pocrates (1861), Oeuvres Completes. Trans. Littré, E. Paris.

Номе, F. (1759), Medical Facts and Experiments.

JoHnson, J. (1813), The Influence of Tropical Climates . . . on European Constitutions, etc.

Jores, A. (1930), 'Perspiratio Insensibilis', Z. ges. exp. Med. LXxi, 170.

KeIl L, J. (1 718 ), Medicina Statica Brittanica, being the Aphorisms of Dr. Keill, etc.

Krause, C. F. T. (1844), 'Wagner, R.', Handwörterbuch der Physiologie. Brunswick.

Lavoisier, A. L., and Se guin, M. (1790), Mém. Acad. Roy. Sci. (Paris).6or.

Lining, J. (1744), Phil. Trans., XIm, 318, 491.

Malphigi, M. (1666), De Viscerum Structura, etc. Bologna.

Meyserey, M. De (1744), La Medecine d'Armée. Paris.

Mitchell, J. (1744), Phil. Trans., XLII, 102

Newburgh, L. H., Wiley, F. H., and Lashmet, F. H. (1931), 'A Method for the determination of heat production over long periods of time', $\mathbf{7}$. clin. Invest., $\mathbf{x}, 703$.

Osborne, J. (1837), On the Nature and Treatment of Dropsical Diseases.

PARE, A. (1554), Works. Trans. from Latine Johnson, J. 1664.

Pettenkofer, M. von (1862), 'Ueber die Respiration', Ann. Chem. Pharm., il, i.

Pinard, M. (1747), Dissertation sur la Fière Miliare, etc., Rouen.

Platner, J. Z. (1752), Tractat der Reinlichkeit. Leipzig.

Power, H. (1664), An Experimental Philosophy in Three Books, etc.

Pringle, J. (1752), Observations on the Diseases of the Army.

Quain, R. (1894), A Dictionary of Medicine. New ed.

Quincy, T. (1720), Ars de Statica Medicina. Trans. into English with large explanations. 2nd ed.

Renbourn, E. T. (1957), 'The History of the Flannel Binder and Cholera Belt', Med. Hist., I, 211.

Renbourn, E. T. (1958), 'The History of Sweat and Prickly Heat, 19th-2oth Century.' 7. Invest. Derm., xxx, 249.

Rig By, E. (1785), An Essay on the Theory of the Production of Animal Heat.

Robertson, B. (1748), A Dissertation on the Food and Discharges of Human Bodies.

SANCTORIUS (1614), Cited by Quincy, T.

SCHÄ FER, E. S. (1898), Text Book of Physiology. Vol. 1.

Steno, N. (1664), Musculi et Glanduli Observationum, etc. Copenhagen.

Theophrastus (1917), Theophrastus and the Greek Physiological Psychology before Aristotle. G. M. Stratton. 


\section{E. T. Renbourn}

Towne, R. (1726), $A$ Treatise on the Diseases most frequent in the West Indies, etc.

TRAPHAM, T. (1679), A Discourse on the State of Health in the Island of Famaica.

Turner, D. (1714), De Morbis Cutaneis. A Treatise on Diseases incident to the Skin.

Vinci, L. DA (1938), The Note Books. Trans. McCurdy, E. Vol. I.

WAINeWRIgHt, J. (1707), A Mechanical Account of the Non Naturals.

Wrstey, J. (1 747), Primitive Physick, etc. Bristol.

Whitehouse, A. G. R., Hancock, W., and Haldane, J. S. (1932), 'The Osmotic passage of water through the Human Skin'. Proc. Roy. Soc. B., cxi, 412.

Winslow, J. B. (1 732), Exposition anatomique de la Structure du Corps Humain. Paris.

\section{ACKNOWLEDGMENTS}

I am greatly indebted to Dr. F. N. L. Poynter and his staff for facilities at the Wellcome Historical Medical Library. 